\title{
Antitumor effects of nadroparin combined with radiotherapy in Lewis lung cancer models
}

This article was published in the following Dove Press journal: OncoTargets and Therapy

\author{
Xibing Zhuang' \\ Tiankui Qiao' \\ Sujuan Yuan' \\ Qi Zhang' \\ Wei Chen' \\ Youjun Luo' \\ Guoxiong $\mathrm{Xu}^{2}$ \\ 'Department of Oncology, Jinshan \\ Hospital, Fudan University, Shanghai, \\ People's Republic of China; \\ ${ }^{2}$ Department of Central Laboratory, \\ Center Laboratory, Jinshan Hospital, \\ Fudan University, Shanghai, People's \\ Republic of China
}

\begin{abstract}
Background: The beneficial antitumor effects of low-molecular-weight heparins (LMWHs) have previously been investigated in basic and clinical studies. In this study, the antitumor efficacy of nadroparin combined with radiotherapy was investigated in vivo.

Methods: A total of 48 tumor-bearing mice were randomly divided into six groups $(\mathrm{n}=8$ per group): control group, irradiation group (X), $\mathrm{LMWH}_{1,000}$ group, $\mathrm{LMWH}_{2,000}$ group, $\mathrm{LMWH}_{1,000}+$ $\mathrm{X}$ group and $\mathrm{LMWH}_{2,000}+\mathrm{X}$ group. Following this, tumor growth, weight and inhibitory rate, as well as the survival of mice in each group, were determined. Levels of serum interleukin (IL)-6 and transforming growth factor (TGF)- $\beta 1$ were determined via enzyme-linked immunosorbent assay (ELISA) analyses. The expression levels of CD34 were investigated using immunohistochemistry analyses to represent the microvascular density (MVD) values of tumor tissues. In addition, tumor cell apoptosis was investigated using TdT-mediated dUTP nick end labeling (TUNEL) analysis post treatment. The expression levels of survivin were analyzed by Western blotting.
\end{abstract}

Results: The volumes and weights of tumors in the treatment groups were demonstrated to be significantly decreased, which was most obvious in the $\mathrm{LMWH}_{2,000}+\mathrm{X}$ group. The tumor inhibitory rate was significantly increased in the treated mice. ELISA assays demonstrated that the concentrations of serum IL- 6 and TGF- $\beta 1$ were significantly decreased in the $\mathrm{LMWH}_{2,000}+$ $\mathrm{X}$ group. In addition, the decreased CD34 expression was found in the combined treatment groups. TUNEL assays demonstrated that the apoptosis rate was increased in treated mice, and the highest apoptosis rate was exhibited by the $\mathrm{LMWH}_{2,000}+\mathrm{X}$ group. Results of Western blotting demonstrated that combinatory treatment with both nadroparin and X-ray irradiation significantly inhibited the expression of survivin.

Conclusion: These results demonstrated that a combinatory treatment strategy of nadroparin with fractionated irradiation had a strong synergistic antitumor effect in vivo, which may be associated with the promotion of apoptosis, inhibited secretion of TGF- $\beta 1$ and IL- 6 and downregulation of CD34 and survivin expression.

Keywords: low-molecular-weight heparins, Lewis lung cancer, X-ray irradiation, microvascular density

\section{Introduction}

Cancer is characterized by uncontrolled cellular growth and distant metastases. Lung cancer is the leading cause of cancer-associated mortality in both men and women worldwide. ${ }^{1}$ The majority of lung cancers are diagnosed at late stages, and the long-term survival rates of patients with lung cancer remain poor. Radiotherapy is an important therapeutic strategy for the treatment of patients with locally advanced non-smallcell lung cancer (NSCLC). ${ }^{2}$ However, the resistance of cancer cells to radiation often results in unsuccessful radiotherapy treatment. Therefore, the development of a safe
Correspondence: Tiankui Qiao Department of Oncology, Jinshan Hospital, Fudan University, 1508 Longhang Road, Shanghai 20I508, People's Republic of China Tel +86 2l 34l89990538। Email qiaotk@।63.com 
and effective combinatory therapy in order to enhance the antitumor effect of radiotherapy is important.

Fraxiparine $^{\circledR}$ (nadroparin; 3-9 kDa) is a low-molecularweight heparin (LMWH) that can be obtained from unfractionated heparin via enzymatic hydrolysis or chemical degradation. Nadroparin is a traditional and safe anticoagulant drug that has been used in clinical practice for many years. In 1983, Rickles and Edwards ${ }^{3}$ suggested that the blood of patients with malignant tumors was in a hypercoagulable state, which would lead to the development of thrombosis if left untreated. Thus, the association between the development of cancer and anticoagulant drugs has attracted wide spread attention. Numerous previous studies have demonstrated that LMWHs exhibit a number of antitumor properties, such as inducing alterations in the cellular and molecular biological environments, which may suppress the development of tumors., ${ }^{4,5}$ Bobek and Kovarík ${ }^{6}$ suggested that the main antitumor mechanisms underlying the effects of LMWHs are as follows: inhibition of the adhesion and migration of tumor cells, dysregulation of the expression of genes associated with cancer, induction of apoptosis of tumor cells or differentiation of programmed cells, suppression of drug resistance exhibited by tumor cells, inhibition of vascular tissue formation in tumors and the activation of natural killer cells. Nadroparin is routinely used as an anticoagulant; however, it is not administered in combination with chemoradiotherapy in clinical practice. In our previous study, it was demonstrated that combinatory treatment with nadroparin and irradiation exhibited a strong, synergistic antitumor effect in a dose- and time-dependent manner in vitro. ${ }^{7}$ Considering the results of the aforementioned studies, nadroparin and X-ray irradiation were used in the present study to treat mice that had been transplanted with tumors to investigate the antitumor effect of combination therapy in vivo. The results of the present study may provide us a theoretical basis for clinical use of nadroparin to enhance the antitumor effect of radiotherapy.

\section{Methods}

\section{Instruments and reagents}

Lewis lung cancer cells used in the present study were supplied by the Shanghai Institute of Life Science, Chinese Academy of Sciences (Shanghai, China) and subsequently cultured in Dulbecco's Modified Eagle's Medium (Thermo Fisher Scientific, Waltham, MA, USA) supplemented with $10 \%$ fetal bovine serum. Cultures were maintained at $37^{\circ} \mathrm{C}$ in a humidified atmosphere containing $5 \% \mathrm{CO}_{2}$. Female C57BL/6J mice $(n=48)$ were provided by the
Shanghai Experimental Animal Center (Shanghai, China) and maintained in specific pathogen-free grade conditions until reaching an age of 6-8 weeks and a weight of 18-22 g (animal license number: SCXK; 2012-0006). Nadroparin (GlaxoSmithKline plc, London, UK) was obtained as a standard drug formulation. The concentrations of interleukin (IL)-6 and transforming growth factor (TGF)- $\beta 1$ in serum were determined using a standard Quantikine enzyme-linked immunosorbent assay (ELISA) kit (Nanjing KeyGen Biotech. Co., Ltd., Nanjing, China). MVD was investigated by immunochemical staining using rabbit anti-mouse polyclonal antibodies (1:50; Boster Biological Technology, Pleasanton, CA, USA). A TdT-mediated dUTP nick end labeling (TUNEL) kit (Nanjing KeyGen Biotech. Co., Ltd.) was used to investigate tumor cell apoptosis. Rabbit monoclonal antibodies against survivin and mouse monoclonal antibodies against GAPDH were purchased from Santa Cruz Biotechnology Inc. (Dallas, TX, USA). A Trilogy 6086 linear accelerator was also purchased (Varian Medical Systems, Palo Alto, CA, USA).

\section{Establishment of the mouse model, groupings and treatment}

Lewis lung cancer cells $\left(\sim 3 \times 10^{6}\right)$ were subcutaneously injected into the right anterior leg of each mouse to establish the tumor-bearing mouse model. A total of 48 mice were randomly separated into six groups: control group (nontreated); irradiation group (X-ray irradiation was administered at 2.5 Gy per day for a total of 5 days [total dose administered was 12.5 Gy X-ray irradiation]), $\mathrm{LMWH}_{1,000}$ group $\left(\mathrm{L}_{1,000}\right.$; treated with $1,000 \mathrm{IU} / \mathrm{kg}$ of nadroparin), $\mathrm{LMWH}_{2,000}$ group $\left(\mathrm{L}_{2,000}\right.$; treated with $2,000 \mathrm{IU} / \mathrm{kg}$ of nadroparin), $\mathrm{LMWH}_{1,000}+\mathrm{X}$-ray irradiation group $\left(\mathrm{X}+\mathrm{L}_{1,000}\right.$; treated with $1,000 \mathrm{IU} / \mathrm{kg}$ of nadroparin and $12.5 \mathrm{~Gy} \mathrm{X}$-ray irradiation) and $\mathrm{LMWH}_{2,000}+\mathrm{X}$-ray irradiation group $\left(\mathrm{X}+\mathrm{L}_{2,000}\right.$; treated with $2,000 \mathrm{IU} / \mathrm{kg}$ of nadroparin and $12.5 \mathrm{~Gy} \mathrm{X}$-ray irradiation). The irradiation mode and dose in the combined treatment groups were the same as that in the X-ray irradiation group. Treatment was initiated for a total of 9 days post inoculation. Nadroparin was administered subcutaneously for a total of 9 days in continuity. Two days post injection of nadroparin, the mice were subjected to X-ray irradiation for a total of 5 days and the groups treated with nadroparin for 2 days following the termination of $\mathrm{X}$-ray irradiation treatment. A total of 18 days post inoculation, three mice were randomly sacrificed in each group for further investigation. The cutoff time interval was defined as 30 days post inoculation based on the previous observation of survival in the 


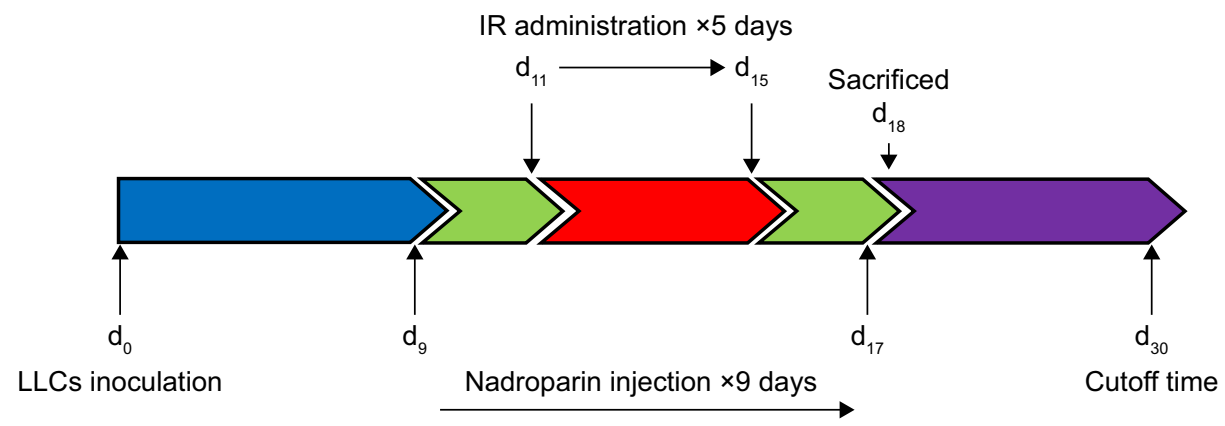

Figure I Experimental procedures.

Abbreviations: d, day; IR, ionizing radiation; LLCs, Lewis lung cancer cells.

xenograft models. The treating strategy is shown in Figure 1. This work was approved by and performed in accordance with the protocols of the ethics committee of Jinshan Hospital, Fudan University (Shanghai, China).

\section{Efficacy of transplanted tumors}

A total of 9 days post inoculation, the tumor volume of the tumor-bearing mice in each group were observed on alternate days to day 17 after inoculation. The tumor volume was determined to establish a tumor growth curve, and the survival time of mice was investigated 30 days post inoculation. Tumor volumes were determined using the following formula: tumor volume $\left(\mathrm{cm}^{3}\right)=1 / 2 \times\left(\right.$ length $[\mathrm{cm}] \times$ width $^{2}$ $[\mathrm{cm}]){ }^{8} \mathrm{~A}$ total of 18 days post inoculation, three mice in each group were sacrificed, and the tumor inhibitory rate was determined using the following formula: tumor inhibitory rate $=1-($ mean tumor weight of treated group/mean tumor weight of control group) $\times 100 \%{ }^{9}$

\section{Cell apoptosis in transplanted tumors}

To determine the rate of cell apoptosis in transplanted tumors, TUNEL assays were performed, which stained apoptotic cell nuclei brown and stained non-apoptotic cells blue. Cell apoptosis was observed using a microscope by two pathologists working independently. A total of $\sim 1,200$ cells were counted in three high-power (magnification $\times 200$ ) microscope fields of vision. The apoptotic rate was calculated using the following formula: (number of apoptotic cells/total number of cells $) \times 100 \%{ }^{10}$

\section{Determination of IL-6 and TGF- $\beta$ I levels in serum}

A total of 18 days post inoculation, three mice in each group were randomly sacrificed and serum samples were collected to determine the concentrations of IL- 6 and TGF- $\beta 1$ using a standard Quantikine ELISA kit.

\section{Determination of MVD in tumors using immunohistochemistry (IHC)}

Transplanted tumor tissues were isolated from the three mice in each group and subsequently fixed, dehydrated, embedded, sliced and dewaxed. Intratumoral blood vessels were investigated via staining of endothelial cells using anti-mouse cluster of differentiation 34 antibodies. MVD was investigated in the areas of each tumor in which the most intense levels of vascularization were observed. Individual microvessel counts were then performed by three independent observers using a field microscope (magnification, $\times 200$ ). The mean counts were subsequently used as the final scores. ${ }^{11}$ MVD values represent the number of microvessels observed per field using a microscope (magnification, $\times 200$ ).

\section{Protein extraction and Western blotting}

Tumor tissues obtained from mice in each experimental group were homogenized in cold lysis buffer with $1 \mathrm{mM}$ phenylmethanesulfonyl fluoride and subsequently lysed for 60 minutes on ice. Protein concentrations were determined via Coomassie Blue Fast Staining (Beyotime Institute of Biotechnology, Shanghai, China). Protein samples (50 $\mu \mathrm{g})$ from each experimental group were separated via $10 \%$ SDS-PAGE and subsequently transferred to polyvinylidene fluoride membranes (EMD Millipore, Billerica, MA, USA). Following this, membranes were blocked using Tris-buffered saline containing Tween 20 and 5\% skimmed milk for 3 hours and subsequently incubated with the survivin antibodies (1:750) overnight at $4^{\circ} \mathrm{C}$. GAPDH antibodies $(1: 15,000)$ were used as an endogenous reference. Following this, membranes were incubated with secondary antibodies $(1: 4,000)$ at room temperature for 1 hour. The blots were then visualized using Immobilon ${ }^{\mathrm{TM}}$ Western Chemiluminescent Horseradish Peroxidase Substrate (EMD Millipore) and the Tanon-4500 Gel Imaging System and subsequently quantified using GIS 
ID Analysis Software v4.1.5 (Tanon Science \& Technology Co., Ltd., Shanghai, China).

\section{Statistical analyses}

SPSS 20.0 (IBM Corporation, Armonk, NY, USA) and GraphPad $^{\text {TM }}$ Prism 5.0 (GraphPad Software, Inc., La Jolla, CA, USA) software were used to perform statistical analyses. Data are expressed as the mean \pm standard error of the mean. Statistical analysis between two groups was performed using the Student's $t$-test. Survival rates were determined using the Kaplan-Meier method, and the log-rank test was used to compare the differences in survival rates among groups. $P<0.05$ was considered to represent a statistically significant difference. All experiments were independently performed in triplicate.

\section{Results}

Tumor volumes in mice treated with nadroparin and X-ray irradiation are decreased in a time-dependent manner. We have previously demonstrated that nadroparin and X-ray irradiation exhibit synergistic antitumor effects in vitro. ${ }^{7}$ In the present study, 48 Lewis lung cancer mouse models were successfully established in order to further investigate the antitumor effects of the combinatory treatment in vivo. The results demonstrated that the treated groups exhibited significantly decreased tumor growth compared with the control group $(P<0.05)$; however, no statistical difference was revealed between the dosage of nadroparin and decreased tumor growth. A total of 9 days post inoculation, there were no significant differences between the tumor volumes exhibited by the six experimental groups (Figure 2). In addition, tumor volumes in the X-ray irradiation group and the combined treatment groups were revealed to decrease in a time-dependent manner following a total of 13 days post inoculation $(P<0.05)$. Compared with the $\mathrm{X}+\mathrm{L}_{2,000}$ group, tumor volumes at the 13-day time interval exhibited by the control group, the $\mathrm{L}_{1,000}$ group and the $\mathrm{L}_{2,000}$ group were statistically different $(P<0.05)$. A total of 17 days post inoculation, the mean tumor volume was $8.991 \pm 1.379 \mathrm{~cm}^{3}$ in the control group, $5.216 \pm 0.547 \mathrm{~cm}^{3}$ in X-ray irradiation group, $6.112 \pm 0.846 \mathrm{~cm}^{3}$ in the $\mathrm{L}_{1,000}$ group, $6.002 \pm 0.870 \mathrm{~cm}^{3}$ in the $\mathrm{L}_{2,000}$ group, $4.176 \pm 0.856 \mathrm{~cm}^{3}$ in the $\mathrm{X}+\mathrm{L}_{1,000}$ group and $3.641 \pm 0.926 \mathrm{~cm}^{3}$ in the $\mathrm{X}+\mathrm{L}_{2,000}$ group.

Tumor weights are decreased and tumor inhibitory rates are increased in mice following treatment with nadroparin and X-ray irradiation. A total of 18 days post inoculation, three mice were randomly sacrificed in each group and the tumor tissue was stripped. As presented in Table 1, the tumor

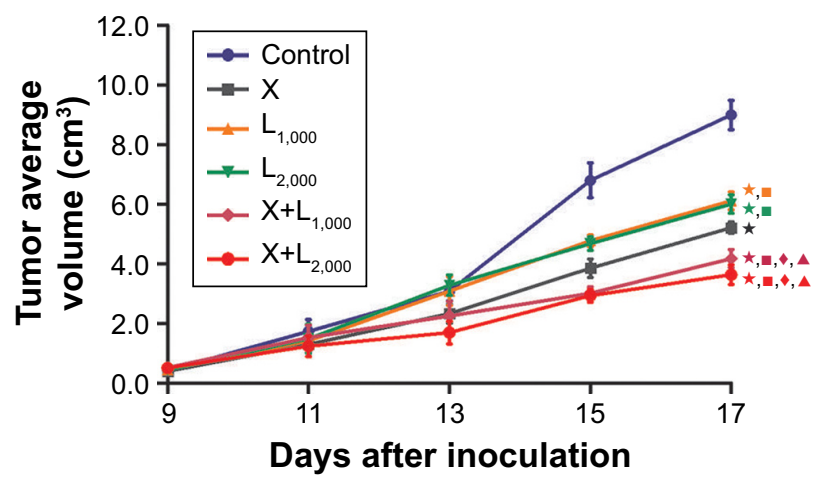

Figure 2 Tumor growth curve.

Notes: Tumor volumes $\left(\mathrm{cm}^{3}\right)$ are presented as the mean \pm standard error of the mean ( $\mathrm{n}=8$ per group). A total of 17 days post inoculation, the mean tumor volumes in the treated groups were decreased compared to those in the control group. The greatest decrease in tumor volume was exhibited by the combined treatment groups. Significant differences in tumor volumes were observed in the treated groups compared with the control group $\left({ }^{\star} P<0.05\right.$; $\mathrm{t}=7.197,5.034,5.185,8.390$ and 9.109). Significant differences in tumor volume were observed in the experimental groups treated with nadroparin alone compared with the $\mathrm{X}$-ray irradiation group, as well as the combined treatment groups compared with the $X$-ray irradiation group $(" P<0.05 ; t=2.517,2.164,2.896$ and 4.141$)$. Significant differences in tumor volume were observed in the combined treatment groups compared with the $L_{1,000}$ group $\left({ }^{*} P<0.05 ; \mathrm{t}=4.552\right.$ and 5.573$)$ and the $L_{2,000}$ group $\left({ }^{\wedge} P<0.05 ; t=4.233\right.$ and 5.256$)$. $X$, X-ray group; $\mathrm{L}_{1,000}, \mathrm{LMWH}_{1,000}$ group - treated with $\mathrm{I}, 000 \mathrm{IU} / \mathrm{kg}$ of nadroparin; $\mathrm{L}_{2,000}, \mathrm{LMWH}_{2,000}$ group - treated with $2,000 \mathrm{IU} / \mathrm{kg}$ of nadroparin; $\mathrm{X}+\mathrm{L}_{1,000}$, $\mathrm{LMWH}_{1,000}+\mathrm{X}$-ray irradiation group - treated with $\mathrm{I}, 000 \mathrm{IU} / \mathrm{kg}$ of nadroparin and I $2.5 \mathrm{~Gy}$ X-ray irradiation; $\mathrm{X}+\mathrm{L}_{2,000}$, $\mathrm{LMWH}_{2,000}+\mathrm{X}$-ray irradiation group - treated with $2,000 \mathrm{IU} / \mathrm{kg}$ of nadroparin and $\mathrm{I} 2.5 \mathrm{~Gy} X$-ray irradiation.

Abbreviation: LMWH, low-molecular-weight heparin.

weight was decreased in the treated groups compared with the control group $(P<0.05)$. Furthermore, the tumor weight was suppressed to the greatest extent in the mice treated with both nadroparin and X-ray irradiation. However, no

Table I Weight and tumor inhibitory rates of tumors obtained from mice ${ }^{\mathrm{d}}$

\begin{tabular}{lllll}
\hline Group & Number & $\begin{array}{l}\text { Tumor } \\
\text { weight }\end{array}$ & P-value & $\begin{array}{l}\text { Tumor } \\
\text { inhibitory } \\
\text { rate (\%) }\end{array}$ \\
\hline Control & 3 & $6.44 \pm 0.6 \mathrm{I}$ & - & - \\
$\mathrm{X}$ & 3 & $4.88 \pm 0.55^{\mathrm{a}}$ & $0.03 \mathrm{I}$ & 24.24 \\
$\mathrm{~L}_{1,000}$ & 3 & $4.85 \pm 0.54^{\mathrm{a}}$ & 0.028 & 24.65 \\
$\mathrm{~L}_{2,000}$ & 3 & $4.92 \pm 0.5 \mathrm{I}^{\mathrm{a}}$ & 0.030 & 23.65 \\
$\mathrm{X}+\mathrm{L}_{1,000}$ & 3 & $3.75 \pm 0.33^{\mathrm{a}-\mathrm{c}}$ & 0.003 & $41.8 \mathrm{I}$ \\
& & & 0.038 & \\
& & & 0.038 & \\
$\mathrm{X}+\mathrm{L}_{2,000}$ & 3 & $3.02 \pm 0.85^{\mathrm{a}, \mathrm{b}, \mathrm{d}}$ & 0.005 & $53.1 \mathrm{I}$ \\
& & & 0.033 & \\
\hline
\end{tabular}

Notes: Data are presented as the mean \pm standard error of the mean. ${ }^{a}<<0.05$ vs control group ( $\mathrm{t}=2.82 \mathrm{I}, 3.370,3.307,4.796$ and 5.663$)$. ${ }^{\mathrm{b} P}<0.05$ vs $\mathrm{X}$-ray irradiation group ( $t=3.059$ and 3.19I). ${ }^{c} P<0.05$ vs $L_{1,000}$ group $(t=3.039)$. ${ }^{d} P<0.05$ vs $L_{2,000}$ group $(\mathrm{t}=3.326) . \mathrm{X}, \mathrm{X}$-ray group; $\mathrm{L}_{1,000}, \mathrm{LMWH}_{1,000}$ group - treated with $1,000 \mathrm{IU} / \mathrm{kg}$ of nadroparin; $\mathrm{L}_{2,000}, \mathrm{LMWH}_{2,000}$ group - treated with $2,000 \mathrm{IU} / \mathrm{kg}$ of nadroparin; $\mathrm{X}+\mathrm{L}_{1,000}$, $\mathrm{LMWH}_{1,000}+\mathrm{X}$-ray irradiation group - treated with $1,000 \mathrm{IU} / \mathrm{kg}$ of nadroparin and I $2.5 \mathrm{~Gy}$ X-ray irradiation; $\mathrm{X}+\mathrm{L}_{2,000}, \mathrm{LMWH}_{2,000}+\mathrm{X}$-ray irradiation group - treated with $2,000 \mathrm{lU} / \mathrm{kg}$ of nadroparin and $12.5 \mathrm{~Gy} X$-ray irradiation.

Abbreviation: LMWH, low-molecular-weight heparin. 


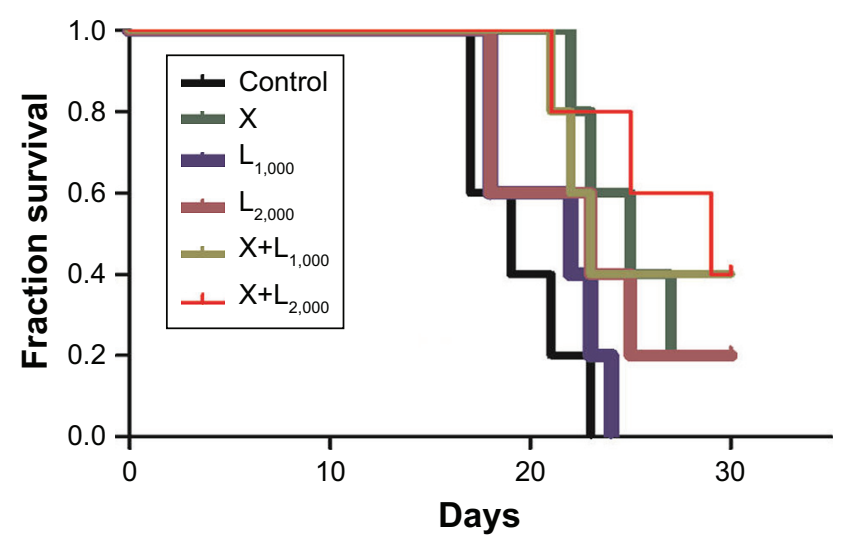

Figure 3 Survival analysis of mice.

Notes: Kaplan-Meier plots of the estimated survival functions for the six experimental groups. Survival times among all of the experimental groups were significantly different $\left(\chi^{2}=4.567 ; P<0.05\right)$. Compared with the control group, the survival time exhibited by the $X$-ray irradiation group and the combined treatment groups was significantly increased $\left(\chi^{2}=6.092,3.876\right.$ and $\left.6.907 ; P<0.05\right)$. The mean survival time of mice was 19.4, 25.4, 21, 22, 25 and 27 days, and the median survival time was 19 , $25,22,23,23$ and 29 days in the control group, $X$-ray irradiation group, $L_{1,000}$ group, $\mathrm{L}_{2,000}$ group, $\mathrm{X}+\mathrm{L}_{1,000}$ group and $\mathrm{X}+\mathrm{L}_{2,000}$ group, respectively. $\mathrm{X}, \mathrm{X}$-ray group; $\mathrm{L}_{1,000}$, $\mathrm{LMWH}_{1,000}$ group - treated with $\mathrm{I}, 000 \mathrm{IU} / \mathrm{kg}$ of nadroparin; $\mathrm{L}_{2,000}, \mathrm{LMWH}_{2,000}$ group treated with $2,000 \mathrm{IU} / \mathrm{kg}$ of nadroparin; $\mathrm{X}+\mathrm{L}_{1,000}, \mathrm{LMWH}_{1,000}+\mathrm{X}$-ray irradiation group treated with $1,000 \mathrm{IU} / \mathrm{kg}$ of nadroparin and $12.5 \mathrm{~Gy} X$-ray irradiation; $\mathrm{X}+\mathrm{L}_{2,000}$, $\mathrm{LMWH}_{2,000}+\mathrm{X}$-ray irradiation group - treated with $2,000 \mathrm{IU} / \mathrm{kg}$ of nadroparin and I 2.5 Gy X-ray irradiation.

Abbreviation: LMWH, low-molecular-weight heparin.

significant statistical difference was determined between the tumor weights exhibited by the $\mathrm{X}+\mathrm{L}_{1,000}$ group and the $\mathrm{X}+\mathrm{L}_{2,000}$ group $(P>0.05)$. Tumor inhibitory rates were $24.24 \%, 24.65 \%, 23.65 \%, 41.81 \%$ and $53.11 \%$ in the five treated groups: $\mathrm{X}$-ray irradiation group, $\mathrm{L}_{1,000}$ group, $\mathrm{L}_{2,000}$ group, $\mathrm{X}+\mathrm{L}_{1,000}$ group and $\mathrm{X}+\mathrm{L}_{2,000}$ group, respectively.

Survival of mice is increased following treatment with nadroparin and X-ray irradiation. Mice treated with nadroparin and X-ray irradiation exhibited a significant effect of increased survival on the overall survival. The Kaplan-Meier plot of the estimated survival functions for the six groups of mice is presented in Figure $3\left(\chi^{2}=4.567\right.$; $P<0.05$ ).

Cell apoptosis is increased in tumors following treatment with nadroparin and X-ray irradiation. Previous studies have demonstrated that heparin induces apoptosis in tumor cells. ${ }^{12,13}$ TUNEL assays were performed to investigate the apoptosis rates exhibited by Lewis lung carcinoma tumors in the present study. As revealed in Figure 4, positive apoptotic cells exhibited small, condensed nuclei; circumscribed nuclear membranes; and brown-stained nuclei. Furthermore, the results revealed that the cell apoptosis rates in treated groups were increased compared with those in the control group, and the most significant increase in apoptosis rates was exhibited by the combined treatment groups $(P<0.05)$. The apoptotic rate exhibited by the $\mathrm{X}+\mathrm{L}_{2,000}$ group was $6.71 \%$. Notably, increased apoptotic rates following nadroparin treatment were not exhibited in a dose-dependent manner.

Treatment with nadroparin and X-ray irradiation decreases concentrations of IL- 6 and TGF- $\beta 1$ in mouse serum. As demonstrated in Figure 5, the concentrations of IL- 6 and TGF- $\beta 1$ in serum were significantly decreased in the treated groups compared with the control group $(P<0.05)$. Furthermore, the combined treatment groups exhibited the most significant decreases in serum IL- 6 and TGF- $\beta 1$ concentrations compared with the control group $(P<0.05)$. Notably, the results revealed that the suppression of IL- 6 and TGF- $\beta 1$ concentrations by nadroparin was not exhibited in a dosedependent manner.

Treatment with nadroparin and X-ray irradiation suppresses MVD in tumors. As revealed in Figure 6, the MVD score was the highest in the control group, and thus the results revealed that tumor microvessel growth was suppressed following treatment with nadroparin and X-ray irradiation. Furthermore, tumor MVD was revealed to be decreased in the combined treatment groups compared with mice treated with nadroparin or X-ray irradiation alone $(P<0.05)$. The inhibitory effect against tumor microvessel angiogenesis observed following treatment with nadroparin was not exhibited in a dose-dependent manner.

Treatment with nadroparin and X-ray irradiation suppresses survivin expression in tumor tissues. Following the results of the previous in vitro study, ${ }^{7}$ the expression of survivin was investigated via Western blotting to determine the molecular mechanism underlying the antitumor effect associated with the combinatory treatment of nadroparin and X-ray irradiation in Lewis lung cancer models. As revealed in Figure 7, the survivin expression in the treated groups was suppressed compared with that in the control group to varying degrees. Furthermore, the expression levels of survivin were decreased to the greatest extent in the combined treatment groups compared with those in the control group $(P<0.05)$. In contrast with the in vitro results, the expression levels of survivin in tumor tissues were not upregulated following treatment with X-ray irradiation, and the inhibitory effect was not dose dependent either.

\section{Discussion}

Lung cancer is the leading cause of cancer-associated death worldwide, and patients with NSCLC exhibit an overall 5 -year survival rate of only $17 \%{ }^{14,15}$ despite the development of numerous individualized treatment strategies for use in 

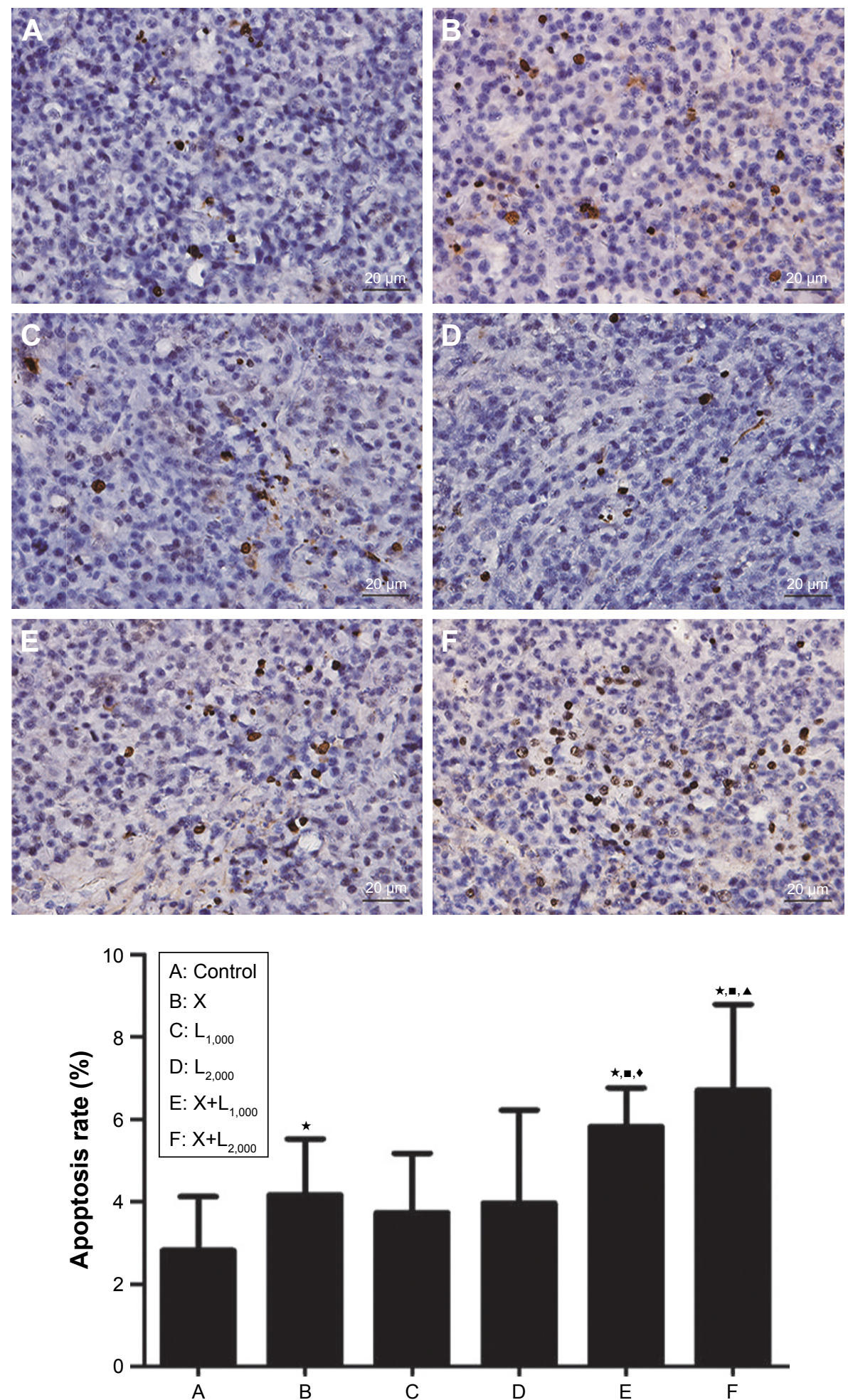

Figure 4 Determination of apoptosis rates in tumor cells.

Notes: Image A-F represents the tumor cell apotosis under 200 -fold microscope in each experimental group, respectively. The cell apoptotic rate was revealed to be the greatest in the combined treatment groups. Significant differences were observed in the X-ray irradiation group and the combined treatment groups compared with the control group $\left({ }^{\star} P<0.05 ; \mathrm{t}=2.152,5.595\right.$ and 4.750$)$. Significant differences were observed in the cell apoptosis rates of the combined treatment groups compared with the $X$-ray irradiation group ( $P<0.05 ; t=3.007$ and 3.066). Significant differences were observed in the $X+L_{1,000}$ group compared with the $L_{1,000}$ group ( $P<0.05 ; t=3.652$ ). Significant differences were observed in $\mathrm{X}+\mathrm{L}_{2000}$ group compared with the $\mathrm{L}_{2000}$ group $\left({ }^{\wedge} \mathrm{P}<0.05 ; \mathrm{t}=2.68 \mathrm{I}\right)$. $\mathrm{X}$, $\mathrm{X}$-ray group; $\mathrm{L}_{1,000}, \mathrm{LMWH}$ $\mathrm{L}_{2,000}, \mathrm{LMWH}_{2,000}$ group - treated with $2,000 \mathrm{IU} / \mathrm{kg}$ of nadroparin; $\mathrm{X}+\mathrm{L}_{1,000}$, $\mathrm{LMWH} \mathrm{H}_{1,000}+\mathrm{X}$-ray irradiation group - treated with $\mathrm{I,000} \mathrm{IU/kg}$ of nadroparin and I2.5 Gy $\mathrm{X}$-ray irradiation; $\mathrm{X}+\mathrm{L}_{2,000}, \mathrm{LMWH}_{2,000}+\mathrm{X}$-ray irradiation group - treated with 2,000 IU/kg of nadroparin and I2.5 Gy X-ray irradiation. The magnification of this image is $\times 200$. Abbreviation: LMWH, low-molecular-weight heparin. 


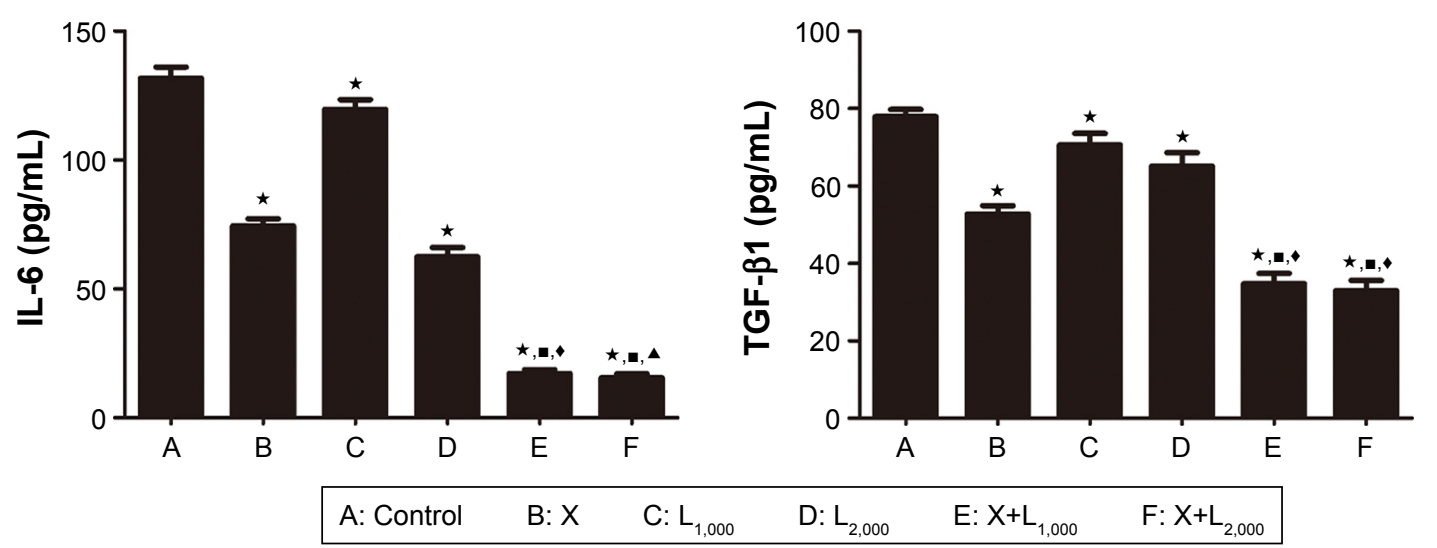

Figure 5 Concentrations of IL-6 and TGF- $\beta$ I in mouse serum.

Notes: An ELISA kit was used to determine TGF- $\beta$ I and IL- 6 levels in mouse serum. The results revealed that the differences in IL- 6 and TGF- $\beta$ I concentrations between the six experimental groups were statistically significant. Significant differences were observed in the treated groups compared with the control group $\left({ }^{\star} P<0.05\right.$; $\mathrm{t}=33.36 \mathrm{I}$, $6.230,36.467,74.477,74.971,26.800,6.253,9.633,40.079$ and 41.894$)$. Significant differences in the concentrations of IL-6 and TGF- $\beta$ I were observed in the combined groups compared with the group treated with $X$-ray irradiation alone ( $P<0.05 ; \mathrm{t}=56.191,56.815,15.966$ and 17.637$)$. Significant differences were observed in the combined treatment groups compared with the $\mathrm{L}_{1,000}$ group $\left({ }^{*} \mathrm{P}<0.05 ; \mathrm{t}=77.104\right.$ and 26.947$)$ and the $\mathrm{L}_{2,000}$ group $\left({ }^{\wedge} \mathrm{P}<0.05 ; \mathrm{t}=35.502\right.$ and 21.775$) . \mathrm{X}, \mathrm{X}-$ ray group; $\mathrm{L}_{1,000}, \mathrm{LMWH} \mathrm{H}_{1,000}$ group - treated with $1,000 \mathrm{IU} / \mathrm{kg}$ of nadroparin; $\mathrm{L}_{2,000}, \mathrm{LMWH}_{2,000}$ group - treated with 2,000 IU/kg of nadroparin; $X+L_{1,000}, L_{M W H}$ with I,000 IU/kg of nadroparin and I2.5 Gy X-ray irradiation; $\mathrm{X}+\mathrm{L}_{2,000}$, $\mathrm{LMWH}_{2,000}+\mathrm{X}$-ray irradiation group - treated with $2,000 \mathrm{IU} / \mathrm{kg}$ of nadroparin and I2.5 Gy X-ray irradiation.

Abbreviations: IL, interleukin; TGF, transforming growth factor; ELISA, enzyme-linked immunosorbent assay; LMWH, low-molecular-weight heparin; MVD, microvascular density.

clinical settings. Thus, numerous studies have investigated NSCLC in order to develop novel and effective therapeutic strategies. ${ }^{16}$

It has been well established that patients with tumors suffer from hypercoagulable states and increased risk of thrombosis. Nadroparin has been used as a therapeutic agent for patients suffering from tumors for many years. Furthermore, nadroparin has been reported to represent an effective therapeutic strategy for the treatment of cancer both in vitro and in vivo; and it has been suggested that the main mechanisms may be associated with anticoagulation, inhibition of selectins, cellular adhesion, angiogenesis regulated by tumor cells, cell cycle and apoptosis. ${ }^{17-20}$ However, the antitumor effect of nadroparin combined with radiotherapy has not been widely studied. Our recent study revealed that nadroparin and irradiation exhibited a strong synergistic antitumor effect in a dose- and time-dependent manner in vitro. ${ }^{7}$ In the present study, the antitumor effects of nadroparin combined with X-ray irradiation, as well as its potential underlying mechanism, were investigated in vivo.

The results of the present study revealed that treatment with nadroparin or X-ray irradiation alone only slightly inhibited tumor growth, while treatment using nadroparin in tumor-bearing mice markedly enhanced the efficacy of fractionated irradiation. Enhancement of the combined treatment response was evident in the significant inhibition of tumor growth and increased survival times of mice compared with mice treated with nadroparin or X-ray irradiation alone.

In recent years, an increasing number of studies have demonstrated that IL- 6 and TGF- $\beta 1$ affect the tumor microenvironment and are associated with the development and prognosis of numerous malignant tumors. ${ }^{21,22} \mathrm{Chen}$ et $\mathrm{al}^{23}$ have reported that the innate TGF- $\beta$ activity of MCF-7 cells was reduced by heparin treatment, with specific interruption of the TGF- $\beta$-Smad signaling pathway. Zhou et al ${ }^{24}$ have found that $X$-ray irradiation promoted migration and invasion of cancer cells through TGF- $\beta$ pathway. Furthermore, studies on IL-6 and LMWHs were also reported. For instance, Shastri et $\mathrm{al}^{25}$ reported that IL- 6 and IL- 8 release from human pulmonary epithelial cells was suppressed by non-anticoagulant fraction of enoxaparin. The results of the present study revealed that serum IL- 6 and TGF- $\beta 1$ levels were markedly decreased in the treated groups compared to the control group, while mice treated with $\mathrm{X}$-ray irradiation combined with nadroparin exhibited significantly decreased expression levels of IL-6 and TGF- $\beta 1$ in serum.

Tumor angiogenesis has an important role in tumor growth and metastasis. ${ }^{26}$ Debergh et al ${ }^{19,27}$ reported that nadroparin inhibits tumor angiogenesis, which results in microvessel normalization in different xenograft models. In the present study, the results demonstrated that MVD value was decreased in the slow growth rate mice. Nadroparin 

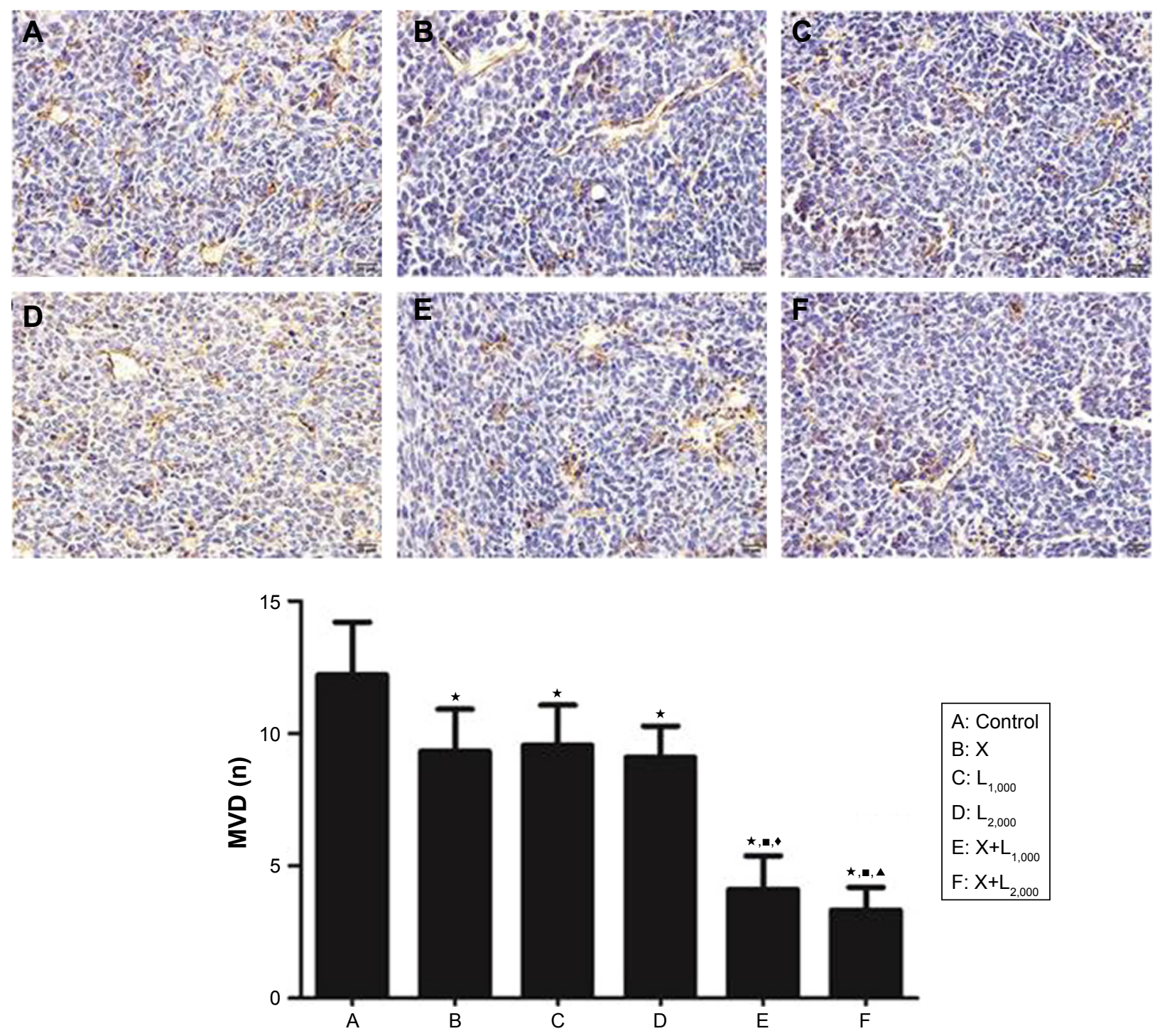

Figure 6 Determination of MVD values in tumor cells.

Notes: Image A-F represents the MVD of tumor tissue under 200-fold microscope in each experimental group, respectively. CD34 immunohistochemical results revealing the expression levels of CD34 and subsequent determination of MVD values. The value of MVD was decreased to the greatest extent in the combined treatment groups. Significant differences were observed between the treated groups compared with the control group $\left({ }^{\star} P<0.05 ; \mathrm{t}=3.414,3.207,4.052\right.$, 10.324 and 12.308). Significant differences were observed in the combined treatment groups compared with the experimental group treated with $X$-ray irradiation alone (" $P<0.05 ; t=7.727$ and 9.985). Significant differences in MVD values were observed in the $X+L_{1,000}$ group compared with the $L_{1,000}$ group ( $P<0.05$; $t=8.283$ ). Significant differences in MVD values were observed in the $X+L_{2,000}$ group compared with the $L_{2,000}$ group $\left({ }^{\wedge} P<0.05 ; t=11.930\right)$. $X, X$-ray group; $L_{1,000}$, $L M W H H_{1,000}$ group - treated with $\mathrm{I}, 000 \mathrm{IU} / \mathrm{kg}$ of nadroparin; $\mathrm{L}_{2,000}, \mathrm{LMWH}_{2,000}$ group - treated with $2,000 \mathrm{IU} / \mathrm{kg}$ of nadroparin; $\mathrm{X}+\mathrm{L}_{1,000}$, $\mathrm{LMWH}_{1,000}+\mathrm{X}-\mathrm{ray}$ irradiation group treated with I,000 IU/kg of nadroparin and I2.5 Gy X-ray irradiation; X+L ${ }_{2,000}$, $\mathrm{LMWH}_{2,000}+\mathrm{X}$-ray irradiation group - treated with $2,000 \mathrm{IU} / \mathrm{kg}$ of nadroparin and I2.5 Gy X-ray irradiation. The magnification of this image is $\times 200$.

Abbreviations: MVD, microvascular density; CD34, cluster of differentiation 34; LMWH, low-molecular-weight heparin.

inhibited angiogenesis, which was not in a dose-dependent manner.

LMWHs may induce cell apoptosis in vivo. ${ }^{28}$ The results of the present study revealed that treatment with nadroparin or X-ray irradiation alone only slightly enhanced the apoptosis rates of tumor cells. The mean apoptosis rate in mice treated with X-ray irradiation was increased compared with mice treated with nadroparin alone; however, there was no significant difference in the apoptosis rates of tumor cells obtained from mice treated with X-ray irradiation alone compared with those obtained from mice treated with nadroparin alone. The effect of increased apoptosis of tumor cells obtained from mice that had been administered treatment with both X-ray irradiation and nadroparin was the most significant.

Numerous scientific studies have demonstrated that survivin has an important role in the development of cancer due to its complex biological functions, including inhibition 

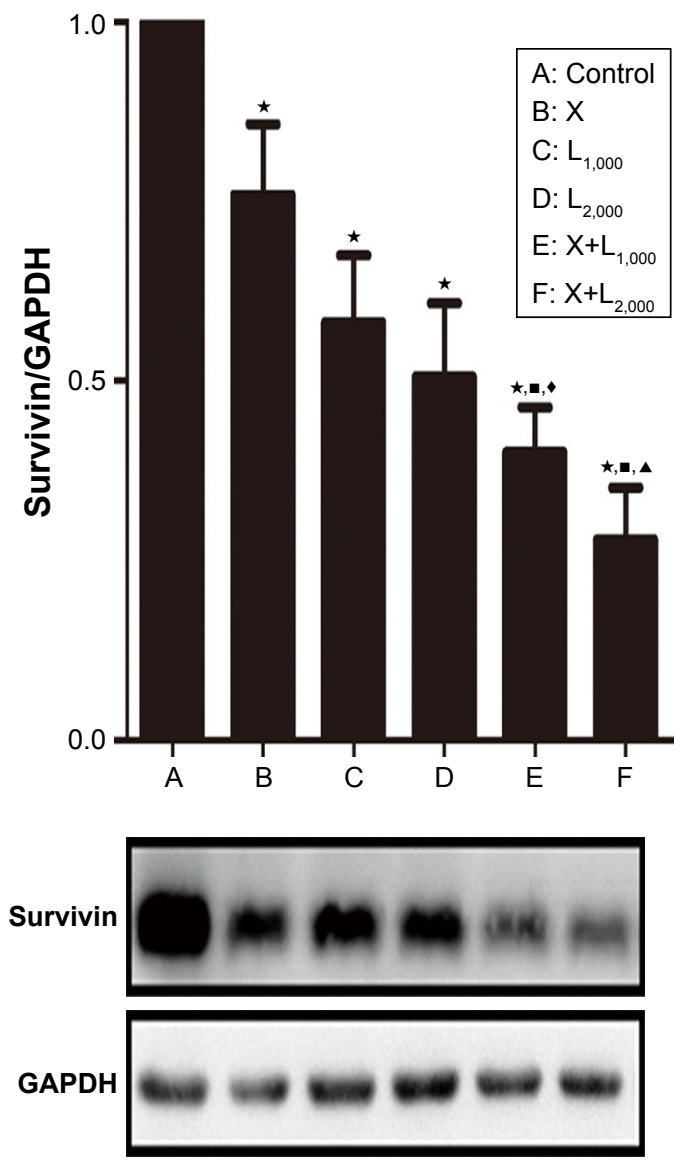

Figure 7 Expression of survivin

Notes: Western blotting demonstrated that survivin was expressed at $16 \mathrm{kDa}$, whereas GAPDH was expressed at $36 \mathrm{kDa}$. The lower part of the picture reveals that the expression of survivin protein was significantly different among each group following treatment, whereas the upper part reveals the relative expression of survivin in each treatment group compared with the control group. Significant differences were observed in the treated groups compared with the control group $\left({ }^{\star} P<0.05\right.$ $\mathrm{t}=4.238,7.750,8.349,16.546$ and 17.160 ). Significant differences in survivin expression were observed in the combined treatment groups compared with the experimental group treated with $X$-ray irradiation alone ( $P<0.05 ; t=5.337$ and 6.813$)$. A significant difference in survivin expression was observed in the $X+L_{1,000}$ group compared with the $L_{1,000}$ group ( $\left.P<0.05 ; t=2.789\right)$. A significant difference in survivin expression was observed in $X+L_{2,000}$ group compared with the $L_{2,000}$ group $\left({ }^{\wedge} P<0.05 ; t=3.126\right)$. $X$, $X$-ray group; $\mathrm{L}_{1,000}$, $\mathrm{LMWH}_{1,000}$ group - treated with I,000 IU/kg of nadroparin; $\mathrm{L}_{2,000}$ $\mathrm{LMWH}_{2,000}$ group - treated with $2,000 \mathrm{IU} / \mathrm{kg}$ of nadroparin; $\mathrm{X}+\mathrm{L}_{1,000}, \mathrm{LMWH}_{1,000}+\mathrm{X}$ ray irradiation group - treated with $1,000 \mathrm{IU} / \mathrm{kg}$ of nadroparin and $12.5 \mathrm{~Gy} X$-ray irradiation; $\mathrm{X}+\mathrm{L}_{2,000}, \mathrm{LMWH}{ }_{2,000}+\mathrm{X}$-ray irradiation group - treated with $2,000 \mathrm{IU} / \mathrm{kg}$ of nadroparin and I $2.5 \mathrm{~Gy} X$-ray irradiation. The magnification of this image is $\times 200$. Abbreviation: LMWH, low-molecular-weight heparin.

of tumor cell apoptosis, promotion of cell proliferation and tumor angiogenesis. ${ }^{29}$ In addition, a previous study revealed that survivin represents an independent prognostic factor for tumor therapy, and its overexpression is correlated with elevated resistance to chemoradiotherapy. ${ }^{30}$ Therefore, blocking tumor cell survivin function or inhibiting its expression may inhibit cell apoptosis and proliferation and enhance its sensitivity to radiotherapy and chemotherapy. In our previous in vitro study, ${ }^{7}$ we have found that nadroparin alone could inhibit not only the expression of survivin but also the upregulated levels of survivin induced by radiotherapy in the combined treatment. In the present study, the results revealed that treatment with nadroparin or X-ray irradiation alone inhibited the expression of survivin to an extent; however, survivin expression was significantly suppressed following treatment with both X-ray irradiation and nadroparin in a non-dose-dependent manner. Therefore, it can be suggested that the antitumor effect of nadroparin combined with X-ray irradiation may be associated with the inhibition of survivin expression in tumor tissues.

\section{Conclusion}

The results of the present study revealed that nadroparin combined with X-ray irradiation exhibited a marked synergistic antitumor effect in vivo. Combined treatment was demonstrated to have inhibited tumor angiogenesis, promoted tumor cell apoptosis, attenuated the tumor microenvironment and inhibited the expression of survivin to a greater extent than treatment with X-ray irradiation or nadroparin alone. Therefore, it can be suggested that combined treatment of $\mathrm{X}$-ray irradiation and nadroparin inhibits tumor growth and improves the survival times of mice with Lewis lung cancer. In contrast to the results demonstrated by in vitro experimentation, the antitumor effects of nadroparin combined with $\mathrm{X}$-ray irradiation were not exhibited in a dose-dependent manner. Furthermore, the promotion of tumor growth induced by X-ray irradiation was not demonstrated during the treatment period. The results of the present study may further the understanding of the mechanism underlying the antitumor effects associated with LMWHs and provide a novel therapeutic strategy for the treatment of patients with lung cancer. However, further investigations are required to determine the molecular mechanisms underlying the antitumor effects of nadroparin administration combined with radiotherapy.

\section{Disclosure}

The authors report no conflicts of interest in this work.

\section{References}

1. Jemal A, Murray T, Ward E, et al. Cancer statistics, 2005. CA Cancer J Clin. 2005;55(1):10-30.

2. Mccloskey P, Balduyck B, van Schil PE, Faivre-Finn C, O'Brien M. Radical treatment of non-small cell lung cancer during the last 5 years. Eur J Cancer. 2013;49(7):1555-1564.

3. Rickles FR, Edwards RL. Activation of blood coagulation in cancer: Trousseau's syndrome revisited. Blood. 1983;62(1):14-31.

4. Ornstein DL, Zacharski LR. The use of heparin for treating human malignancies. Haemostasis. 1999;29(suppl S1):48-60.

5. Sudha T, Phillips P, Kanaan C, Linhardt RJ, Borsig L, Mousa SA. Inhibitory effect of non-anticoagulant heparin (S-NACH) on pancreatic cancer cell adhesion and metastasis in human umbilical cord vessel segment and in mouse model. Clin Exp Metastasis. 2012;29(5):431-439. 
6. Bobek V, Kovarík J. Antitumor and antimetastatic effect of warfarin and heparins. Biomed Pharmacother. 2004;58(4):213-219.

7. Zhuang X, Qiao T, Xu G, Yuan S, Zhang Q, Chen X. Combination of nadroparin with radiotherapy results in powerful synergistic antitumor effects in lung adenocarcinoma A549 cells. Oncol Rep. 2016;36(4):2200-2206

8. Zhang J, Tian H, Li C, et al. Antitumor effects obtained by autologous Lewis lung cancer cell vaccine engineered to secrete mouse interleukin 27 by means of cationic liposome. Mol Immunol. 2013;55(3-4):264-274.

9. Zhao N, Wang L, Mou HY, Liang M, Yue W. Synergism and attenuation effects of taurine on cyclophosphamide. Ai Zheng. 2009; 28(3):244-248.

10. Zhou HB, Chen JM, Cai JT, du Q, Wu CN, Cn W. Anticancer activity of genistein on implanted tumor of human SG7901 cells in nude mice. World J Gastroenterol. 2008;14(4):627-631.

11. Mattern J, Koomägi R, Volm M. Association of vascular endothelial growth factor expression with intratumoral microvessel density and tumour cell proliferation in human epidermoid lung carcinoma. $\mathrm{Br} J$ Cancer. 1996;73(7):931-934.

12. Dredge K, Hammond E, Handley P, et al. PG545, a dual heparanase and angiogenesis inhibitor, induces potent anti-tumour and anti-metastatic efficacy in preclinical models. Br J Cancer. 2011;104(4):635-642.

13. Li Y, Liu H, Huang YY, et al. Suppression of endoplasmic reticulum stress-induced invasion and migration of breast cancer cells through the downregulation of heparanase. Int J Mol Med. 2013;31(5): $1234-1242$

14. Jemal A, Siegel R, Ward E, Hao Y, Xu J, Thun MJ. Cancer statistics, 2009. CA Cancer J Clin. 2009;59(4):225-249.

15. Molina JR, Yang P, Cassivi SD, Schild SE, Adjei AA. Non-small cell lung cancer: epidemiology, risk factors, treatment, and survivorship. Mayo Clin Proc. 2008;83(5):584-594.

16. Herbst RS, Heymach JV, Lippman SM. Lung cancer. $N$ Engl J Med. 2008;359(13):1367-1380.

17. Carmazzi $\mathrm{Y}$, Iorio $\mathrm{M}$, Armani $\mathrm{C}$, et al. The mechanisms of nadroparinmediated inhibition of proliferation of two human lung cancer cell lines. Cell Prolif. 2012;45(6):545-556.

18. Norrby K. Low-molecular-weight heparins and angiogenesis. APMIS. 2006;114(2):79-102.

19. Debergh I, van Damme N, Pattyn P, Peeters M, Ceelen WP. The lowmolecular-weight heparin, nadroparin, inhibits tumour angiogenesis in a rodent dorsal skinfold chamber model. Br J Cancer. 2010;102(5): $837-843$.
20. Yin W, Zhang J, Jiang Y, Juan S. Combination therapy with low molecular weight heparin and Adriamycin results in decreased breast cancer cell metastasis in $\mathrm{C}_{3} \mathrm{H}$ mice. Exp Ther Med. 2014;8(4):1213-1218.

21. Salgado R, Junius S, Benoy I, et al. Circulating interleukin-6 predicts survival in patients with metastatic breast cancer. Int $J$ Cancer. 2003;103(5):642-646.

22. Kang $\mathrm{X}$, Kong $\mathrm{F}, \mathrm{Wu} \mathrm{X}$, et al. High glucose promotes tumor invasion and increases metastasis-associated protein expression in human lung epithelial cells by upregulating heme oxygenase-1 via reactive oxygen species or the TGF- $\beta 1 / \mathrm{PI} 3 \mathrm{~K} /$ Akt signaling pathway. Cell Physiol Biochem. 2015;35(3):1008-1022.

23. Chen Y, Scully M, Dawson G, et al. Perturbation of the heparin/ heparin-sulfate interactome of human breast cancer cells modulates pro-tumourigenic effects associated with PI3K/Akt and MAPK/ERK signalling. Thromb Haemost. 2013;109(6):1148-1157.

24. Zhou YC, Liu JY, Li J, et al. Ionizing radiation promotes migration and invasion of cancer cells through transforming growth factor-betamediated epithelial-mesenchymal transition. Int J Radiat Oncol Biol Phys. 2011;81(5):1530-1537.

25. Shastri MD, Stewart N, Horne J, et al. In-vitro suppression of IL-6 and IL-8 release from human pulmonary epithelial cells by non-anticoagulant fraction of enoxaparin. PLoS One. 2015;10(5):e0126763.

26. Shinkaruk S, Bayle M, Laïn G, Déléris G. Vascular endothelial cell growth factor (VEGF), an emerging target for cancer chemotherapy. Curr Med Chem Anticancer Agents. 2003;3(2):95-117.

27. Debergh I, Pattyn P, Ceelen W. Microvascular effects of the low molecular weight heparins in a colorectal xenograft model: an intravital microscopy study. J Surg Res. 2015;194(2):488-495.

28. Bae SM, Kim JH, Chung SW, et al. An apoptosis-homing peptideconjugated low molecular weight heparin-taurocholate conjugate with antitumor properties. Biomaterials. 2013;34(8):2077-2086.

29. Nassar A, Lawson D, Cotsonis G, Cohen C. Survivin and caspase-3 expression in breast cancer: correlation with prognostic parameters, proliferation, angiogenesis, and outcome. Appl Immunohistochem Mol Morphol. 2008;16(2):113-120.

30. Yoshida H, Sumi T, Hyun Y, et al. Expression of survivin and matrix metalloproteinases in adenocarcinoma and squamous cell carcinoma of the uterine cervix. Oncol Rep. 2003;10(1):45-49.
OncoTargets and Therapy

\section{Publish your work in this journal}

OncoTargets and Therapy is an international, peer-reviewed, open access journal focusing on the pathological basis of all cancers, potential targets for therapy and treatment protocols employed to improve the management of cancer patients. The journal also focuses on the impact of management programs and new therapeutic agents and protocols on

\section{Dovepress}

patient perspectives such as quality of life, adherence and satisfaction The manuscript management system is completely online and includes a very quick and fair peer-review system, which is all easy to use. Visit http://www.dovepress.com/testimonials.php to read real quotes from published authors. 